\title{
Numerical Mathematical Simulation of Penetration of Indenters of Different Shapes During Strengthening Machine Parts via Local Loading of Deformation Zone
}

\author{
O.V. Pilipenko \\ Orel State University (OSU) \\ Orel, Russian Federation \\ V.A. Golenkov \\ Orel State University (OSU) \\ Orel, Russian Federation
}

\author{
S.Y. Radchenko \\ Orel State University (OSU) \\ Orel, Russian Federation \\ D.O. Dorohov \\ Orel State University (OSU) \\ Orel, Russian Federation
}

\begin{abstract}
Numerical mathematical simulation of the strengthening combined local loading of the deformation zone in the process of penetration of indenters of different shapes into the piece body was considered. The simulation results were presented in the form of the pattern corresponding to the Odkvist parameter change depending on the type of the tool and the depth (force) of its penetration into the piece body. Based on the analysis of numerical mathematical simulation data, practical recommendations have been formulated pertinent to the selection of the indenter shape for the processes of gradient strengthening of machine parts in the conditions of combined local loading of the deformation zone.
\end{abstract}

Keywords-numerical mathematical simulation, gradient strengthening of machine parts, combined local loading of the deformation zone, Odkvist parameter, strengthening depth.

\section{INTRODUCTION}

The modern development of the strengthening process via plastic metalworking of different machine parts requires finding a balance between the operational parameters (wear resistance, strength, durability) of the finished product and the cost of its manufacturing. Among the advanced methods of such treatment of axisymmetric products, there are those in which roller tools are used. Essentially, such tools act as indenters, which penetrate into the piece material and strengthen the piece body while the tool moves relative to it. A common example of such method is the roller or ball burnishing process; more complex and efficient schemes of such treatment are represented by the processes that are based on the combined local loading of the deformation zone (CLL deformation). CLL deformation processes are defined as the processes, in which the plastic deformation zone is intentionally created via applying two or more loads, one of which exerts an effect on the substantial piece volume (global loading), while another load bears a local character and creates a mobile deformation zone, which is characterized by a complex stress state [1-11]. In practice, this method may be realized in the form of the scheme shown in Fig. 1 [12-13].

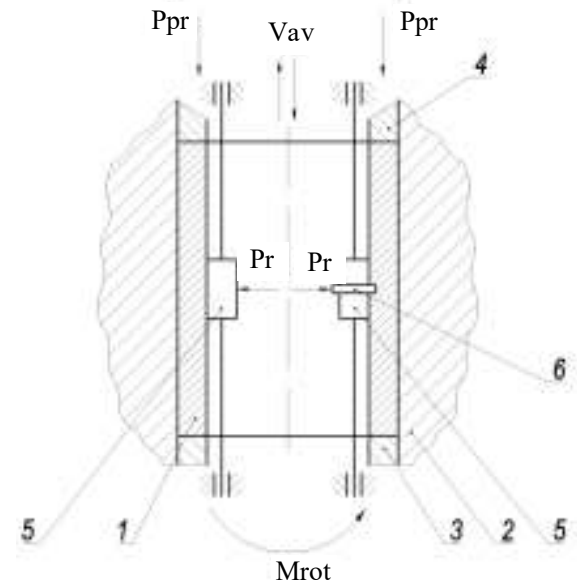

Fig. 1. Scheme illustrating the method for strengthening the internal surface of such parts as collars via roller burnishing: 1 - piece; 2 - container; 3 - rest; 4 - presser; 5 - roller; 6 - deforming protrusion on the roller; $\mathrm{P}_{\mathrm{r}}$ - radial force; $\mathrm{M}_{\mathrm{rot}}$ - rotational moment; $\mathrm{P}_{\mathrm{pr}}-$ axial pressing force; $\mathrm{V}_{\mathrm{av}}$ - axial moving velocity of the burnishing tool.

The method is realized as follows. Piece 1 is placed into container 2, where it is fixed. The rest 3 and presser 4 act as axial arresting devices. Then the process tool equipped with rollers 5 is inserted into the hole in the piece; some of these rollers are smooth; however, one or more rollers are designed with ring-shaped deforming protrusion 6 . The rollers are pressed to treated piece 1 under radial force $\mathrm{P}_{\mathrm{r}}$. The device rotates under rotational moment Mrot and moves in the axial direction with velocity $\mathrm{V}_{\mathrm{av}}$.

\section{STATEMENT OF THE PROBLEM}

It is obvious that the process of mathematical simulation of the considered problem may be divided into two stages (see 
Fig. 2). In Fig. 2, the elementary penetration acts of the forming and smoothing tools during strengthening CLL deformation are illustrated; in this case, the act is repeated relative to the generating line with shifting by feed pitch $\mathrm{s}$. The left Fig. 2a corresponds to the penetration moment of the tool with the creation of the rear and front waves (in consequence of the longitudinal feed, these waves are generally different), which is the equivalent of the roller and/or ball burnishing process. Then deformation in the cross section is realized by rollers, which "smooth" the contact patch (Fig. 2b). Thus, the shape of the part at a first approximation is restored.

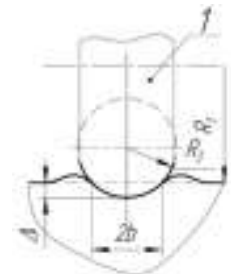

a)

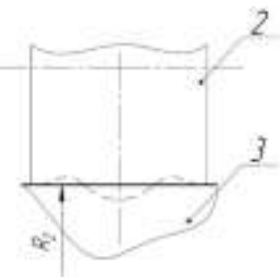

b)
Fig. 2. Elementary deformation act of the part surface during the strengthening CLL deformation: 1 - forming tool (indenter), 2 - smoothing tool, 2 - treated part.

The process scheme shown in Fig. 2a is the subject of mathematical simulation considered in this paper; the analytical (computational) model is presented in Fig. 3.

The boundary conditions for analysis were formulated as follows:

for the parts, which touch the deforming roller (indenter) (Fig. 3, ref. number 1), shifting into the tool is prohibited;

for the parts, which touch the shaded area (Fig. 3), any shifts are prohibited.

The indenters, the shape of which is shown in Fig. 4, will be used as the penetrating tools.

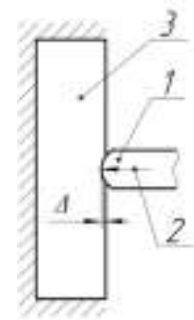

Fig. 3. The analytical model of the elementary penetration act of the forming tool during strengthening CLL deformation: 1 - deforming roller (indenter), 2 - single penetration contour of the deforming roller by the pitch $\Delta, 3$ - the piece.

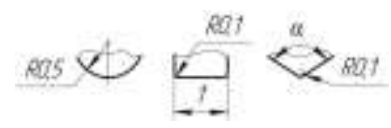

Fig. 4. The shapes of the rollers (indenters), which have been used in the mathematical simulation of the process of the single penetration act of the forming tool, $\alpha=60^{\circ} ; 90^{\circ} ; 120^{\circ} ; 150^{\circ}$.
During the treatment process, the greatest stresses and strains arise at the piece surface, which contacts with the indenter (Fig. 3, ref. number 1; Fig. 4). That is why, in order to obtain the most valid pattern of the stress-strain state of the material, the finite elements triangulation network was applied, which was denser in the area of contact with the tool (Fig. 5). In other areas of the piece, its density was lower, and this simplification permited to reduce the time required for the fulfillment of the necessary calculations without loss of quality of the results.

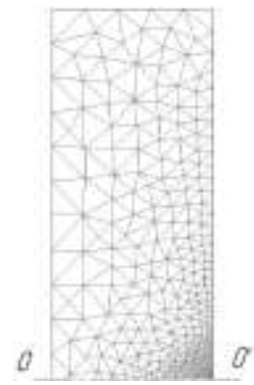

Fig. 5. Finite elements triangulation network section (OO' is the line of symmetry for the finite elements triangulation network).

During numerical simulation, the depths of indenters penetration associated with the piece thickness were prescribed (see the analytical model in Fig. 3): $\Delta_{r}=0.002 ; 0.004 ; 0.008 ; 0.012 ; 0.016 ; 0.020$, as well as the shape of the indenter's body varied (see Fig. 4). The numerical simulation was performed using the application software package SHTAMP 2.0 [14-18].

\section{RESULTS}

Based on the results of the numerical simulation, the software package SHTAMP 2.0 allows plotting the relative isolines of hydrostatic pressure (average normal stress) (see Figs. 6, 7):

$$
p_{r}=\frac{p}{\sigma_{0}}=\frac{\sigma_{x x}+\sigma_{y y}+\sigma_{z z}}{3 \cdot \sigma_{0}},
$$

where $\sigma_{\mathrm{xx}}, \sigma_{\mathrm{yy}}, \sigma_{\mathrm{zz}}-$ primary normal stresses.

Besides, the software package SHTAMP 2.0 allows determining the maximum value pr, which corresponds to the penetration force $\mathrm{P}$ and acts on the piece contact surface under the indenter, as well as plotting the Odkvist parameter isolines (Figs. 6, 7), which, in turn, helps to determine the strengthening depth and its gradient.

In order to select one or another shape of the tool, one can compare the maximum value of Odkvist parameter $\mathrm{q}$ and relative strengthening depth $h \mu$ (the ratio of $h \mu$ to the piece thickness) at different penetration depths (see Figs. 8, 9). The data on the values of relative hydrostatic pressure are presented in Table 1 . 
TABLE 1. THE VALUES OF RELATIVE HYDROSTATIC PRESSURE

\begin{tabular}{|c|c|c|c|c|c|c|}
\hline Indicator & \multicolumn{6}{|c|}{ Data } \\
\hline $\begin{array}{l}\text { Relative penetration } \\
\text { depth }\end{array}$ & $\begin{array}{l}0.00 \\
2\end{array}$ & $\begin{array}{l}0.00 \\
4\end{array}$ & $\begin{array}{l}0.00 \\
8\end{array}$ & $\begin{array}{l}0.01 \\
2\end{array}$ & $\begin{array}{l}0.01 \\
6\end{array}$ & $\begin{array}{l}0.02 \\
0\end{array}$ \\
\hline $\begin{array}{l}\text { Roller with the } \\
\text { protrusion angle of } 60^{\circ}\end{array}$ & 6.59 & 8.05 & 9.53 & $\begin{array}{l}10.6 \\
5 \\
\end{array}$ & $\begin{array}{l}11.4 \\
5 \\
\end{array}$ & $\begin{array}{l}11.8 \\
0\end{array}$ \\
\hline $\begin{array}{l}\text { Roller with the } \\
\text { protrusion angle of } 90^{\circ}\end{array}$ & 6.46 & 7.93 & 8.89 & 9.89 & $\begin{array}{l}10.7 \\
4 \\
\end{array}$ & $\begin{array}{l}11.0 \\
9\end{array}$ \\
\hline $\begin{array}{l}\text { Roller with the } \\
\text { protrusion angle of } \\
120^{\circ}\end{array}$ & 6.28 & 6.85 & 7.52 & 7.70 & 7.77 & 7.79 \\
\hline $\begin{array}{l}\text { Roller with the } \\
\text { protrusion angle of } \\
150^{\circ}\end{array}$ & 4.48 & 4.64 & 4.52 & 4.45 & 4.47 & 4.49 \\
\hline $\begin{array}{l}\text { Roller with the } \\
\text { cylindrical protrusion }\end{array}$ & 3.27 & 4.39 & 4.97 & 5.79 & 6.68 & 7.54 \\
\hline $\begin{array}{l}\text { Roller with the toroidal } \\
\text { protrusion }\end{array}$ & 4.63 & 4.83 & 5.16 & 5.90 & 6.57 & 7.16 \\
\hline
\end{tabular}

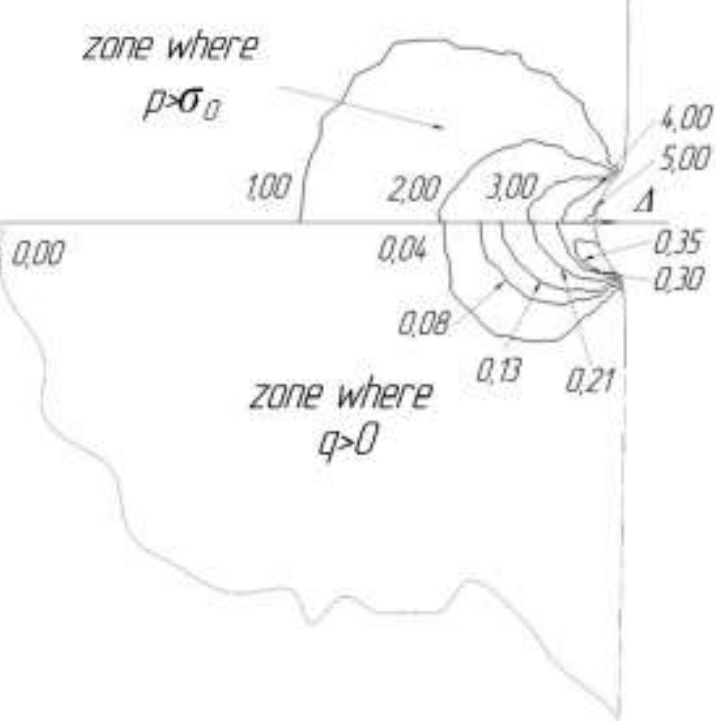

Fig. 6. Isolines of relative hydrostatic pressure pr and Odkvist parameter $\mathrm{q}$ at the relative penetration depth of $\Delta \mathrm{r}=0.02$, indenter - roller with toroidal protrusion, see Fig. 4.

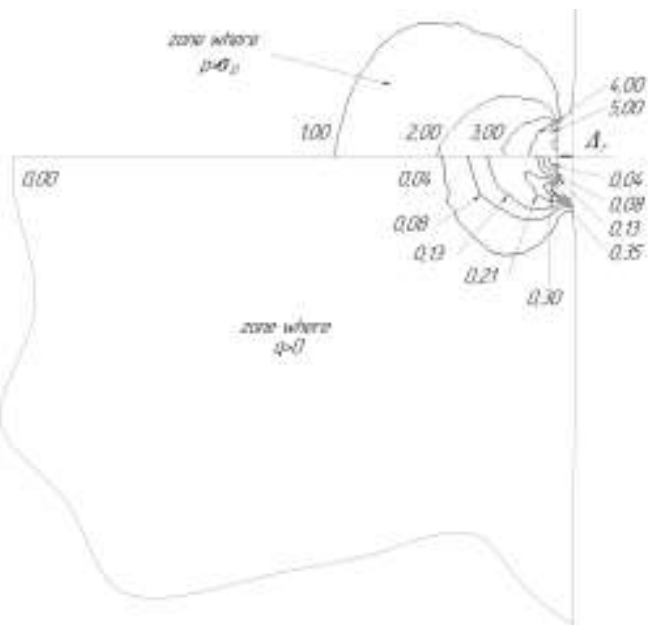

Fig. 7. Isolines of relative hydrostatic pressure pr and Odkvist parameter $q$ at the relative penetration depth of $\Delta \mathrm{r}=0.02$, indenter - roller with cylindrical protrusion, see Fig. 4.

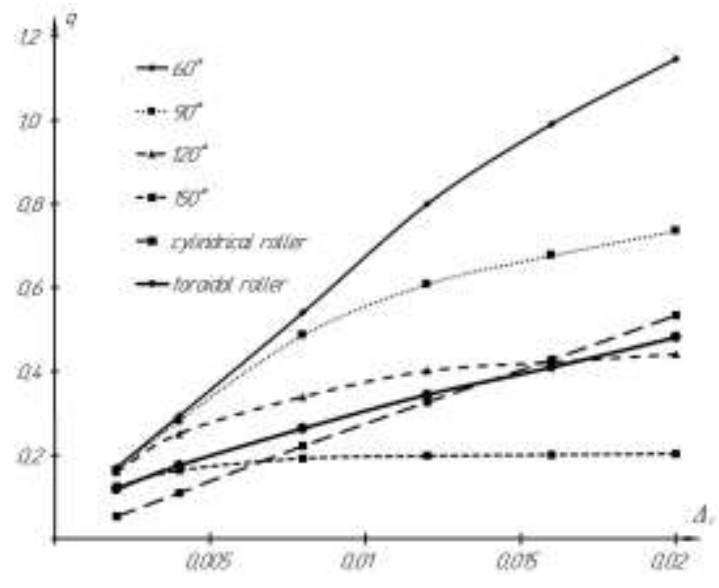

Fig. 8. Maximum values of the Odkvist parameter with different penetration depths values and indenter shapes.

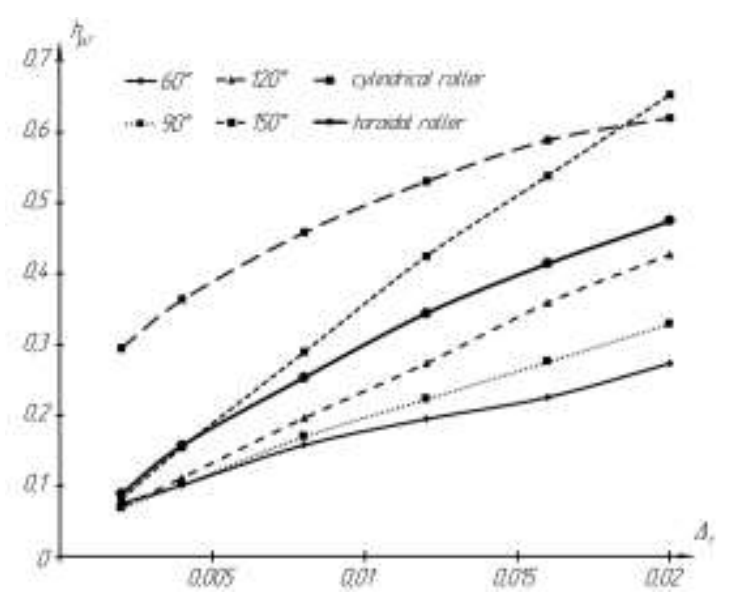

Fig. 9. The values of relative strengthening depth at different penetration depths values and indenter shapes.

\section{DISCUSSION}

From the data presented in Figs. 8 and 9, it follows that the rollers with the protrusion angles of $60^{\circ}$ and $90^{\circ}$ provide the greatest maximum values of the Odkvist parameter, while the values of strengthening depth in these cases are less than in case of other indenters. High q values are concentrated in the surface layers, which is undesirable, since if strengthening will be finally realized following the CLL deformation scheme, it will result in the early damage of the piece surface. The data presented in Table 1 also testify to high pr values for this type of tools, which correspond to higher forces exerted by the deforming tool and, respectively, higher energy consumption than in case of the other roller types. Therefore, deformation using such type of rollers is inexpedient and, which is more important, will bring to substantial damage of the surface during the longitudinal feed, which is used in the processes of the strengthening CLL deformation. While comparing the other considered types of the indenter shapes (see Figs. 8, 9 and Table 1), the conclusion may be drawn that the maximum values of the Odkvist parameter for the rollers with cylindrical 
and toroidal protrusions, as well as for the roller with the protrusion angle of $120^{\circ}$, are quite near to each other (these values are almost the same at $\Delta r=0.016$ ). The values of the relative strengthening depth for the roller with the cylindrical protrusion and for the roller with the protrusion angle of $150^{\circ}$ are near to each other. The values of hydrostatic pressure for the rollers with the cylindrical and toroidal protrusions are near to each other, while the values of hydrostatic pressure for the roller with the protrusion angle of $120^{\circ}$ are relatively large. The values of the relative strengthening depth at different penetration depths for the roller with the protrusion angle of $120^{\circ}$ are less than for the other considered types of indenters. Therefore, this shape of the deforming tool should be also excluded from further consideration.

Eventually, it seems appropriate to study in more detail the "traditional" tools, which are rollers with cylindrical and toroidal protrusions, and additionally the roller with the protrusion angle of $150^{\circ}$. It should be emphasized that for the latter tool, the growth of the maximum value of the Odkvist parameter and of relative hydrostatic pressure is not observed with an increase in the penetration depth, while the strengthening depth increases almost linearly.

Let us consider in more detail the distribution of the relative stresses along three axes for the selected types of tools:

$$
\sigma_{x r}=\frac{\sigma_{x x}}{\sigma_{0}} ; \sigma_{y r}=\frac{\sigma_{y y}}{\sigma_{0}} ; \sigma_{z r}=\frac{\sigma_{z z}}{\sigma_{0}},
$$

as a function of the relative penetration depth of the indenters. The results obtained from the mathematical simulation of the process, which has been realized using the SHTAMP 2.0 software, are presented in Table 2. From these results, it follows that values $\sigma_{\mathrm{xr}}, \sigma_{\mathrm{yr}}$ and $\sigma_{\mathrm{zr}}$ for the toroidal and flat rollers grow with an increase in the penetration depth.

For the roller with the protrusion angle of $150^{\circ}$, the $\sigma_{\mathrm{xr}}$ value is almost constant; $\sigma_{\mathrm{yr}}$ gradually increases, while $\sigma_{\mathrm{zr}}$ decreases. This fact explains the approximate constancy of hydrostatic pressure in case of roller penetration characterized by the protrusion angle of $150^{\circ}$. Thus, this shape of the considered tool provides hindering of the plastic yield of the material in a transverse direction ( $\sigma_{\mathrm{zr}}$ value decreases) in case of an increase in the penetration depth. This is the reason why an increase in the strengthening depth has been observed in the mathematical model.

The mentioned specific feature of the rollers with the protrusion angle of $150^{\circ}$ was proved out in the study [19], in which the following equation was presented:

$$
\frac{\bar{p}}{Y}=\frac{2}{3}\left[1+\ln \left(\frac{1}{3} \cdot \frac{E}{Y} \cdot \operatorname{tg} \beta\right)\right],
$$

where $\mathrm{Y}$ - average contact pressure,

$\bar{p}$ - hydrostatic pressure,

E - Young's modulus of the material,

$\beta$ - angle between the tool and the flat surface.
TABLE 2. DISTRIBUTION OF THE RELATIVE STRESSES ALONG THREE AXES AS A FUNCTION OF THE RELATIVE DEPTH OF THE

\begin{tabular}{|c|c|c|c|}
\hline$\Delta_{r}$ & $\sigma_{x r}$ & $\sigma_{y r}$ & $\sigma_{z r}$ \\
\hline \multicolumn{4}{|c|}{ roller with the protrusion angle of $150^{\circ}$} \\
\hline 0.002 & 5.55 & 3.57 & 4.31 \\
\hline 0.004 & 5.77 & 3.85 & 4.30 \\
\hline 0.008 & 5.71 & 4.05 & 3.81 \\
\hline 0.012 & 5.61 & 4.19 & 3.55 \\
\hline 0.016 & 5.62 & 4.27 & 3.53 \\
\hline 0.020 & 5.63 & 4.32 & 3.51 \\
\hline \multicolumn{4}{|c|}{ roller with the cylindrical protrusion } \\
\hline 0.002 & 3.91 & 2.71 & 3.20 \\
\hline 0.004 & 5.24 & 3.58 & 4.36 \\
\hline 0.008 & 6.15 & 4.30 & 4.50 \\
\hline 0.012 & 7.10 & 4.89 & 5.42 \\
\hline 0.016 & 7.98 & 5.41 & 6.64 \\
\hline 0.020 & 8.62 & 6.48 & 7.51 \\
\hline \multicolumn{4}{|c|}{ roller with the toroidal protrusion } \\
\hline 0.002 & 5.65 & 3.82 & 4.41 \\
\hline 0.004 & 5.88 & 4.12 & 4.50 \\
\hline 0.008 & 6.28 & 4.57 & 4.62 \\
\hline 0.012 & 6.97 & 5.20 & 5.52 \\
\hline 0.016 & 7.62 & 5.90 & 6.20 \\
\hline 0.020 & 8.19 & 6.52 & 6.77 \\
\hline
\end{tabular}
ROLLERS PENETRATION

The equation (2) can be transposed as follows:

$$
\bar{p}=\frac{2}{3}\left[Y+Y \cdot \ln \left(\frac{1}{3} \cdot \frac{E}{Y}\right)+Y \cdot \ln (\operatorname{tg} \beta)\right] \text {. }
$$

Let us consider the problem pertinent to the relation between the minimum value of average contact pressure and the hydrostatic pressure value. It is evident that it may be solved in case when the value in square brackets will maximally not be related to the $\mathrm{Y}$ value, i.e.:

$$
Y=-Y \cdot \ln (\operatorname{tg} \beta)
$$

or

$$
\ln (\operatorname{tg} \beta)=-1
$$

As the result of the solution of this equation, one can obtain $\beta \approx 20^{\circ}$. Then the apex angle of the tool will be equal to $\alpha \approx 140^{\circ}$, which is near to the considered value of $150^{\circ}$.

It should be noted that the absence of growth of the maximum value of the Odkvist parameter (which corresponds to the surface layers) for the roller with the protrusion value of $150^{\circ}$ and its small value in general, as compared with other indenters, evidences the small final strengthening gradient, since the hardness grows with the increase in the q parameter.

To make the picture complete, let us consider the stresses distribution at a maximum calculated relative penetration depth of $\Delta r=0.020$ (Fig. 10). From this figure, it follows that the distribution patterns for the cylindrical roller and for the roller with the protrusion angle of $150^{\circ}$ coincide with each other, and these patterns are similar as compared with the pattern for the toroidal roller.

It is important to compare the boundary patterns for the zones with the compression and tension shear stresses (Fig. 
11). It should be noted that in case of an elementary penetration act, the values of tension stresses do not exceed $\sigma 0$; however, it may happen in the case of longitudinal feed and repeated passage of the tool. Therefore, from the data presented in Fig. 11, it follows that treatment with a toroidal roller is preferred since the zone characterized by $\tau_{\mathrm{xy}}<0$ is small as compared with zones for other tools.

Finally, the following recommendations on the selection of the indenter shapes may be given:

- the roller with the cylindrical protrusion should be used in cases, when high values of the surface hardness and large strengthening depth are required; however, this is accompanied by large energy consumption, there also is the risk of the surface damage in consequence of the availability of a large zone of shear tension stresses;

- the roller with the protrusion angle of $150^{\circ}$ should be used in cases, when it is necessary to create a structure with the large strengthening depth and the assured small damage of the surface layers of the product (excessive cold-work hardening); however, the strengthening degree and gradient will be small;

- the roller with the toroidal protrusion allows realizing high values of surface hardness at a relatively large strengthening gradient; however, the energy consumption will be less than in case of the cylindrical roller and the zone characterized by tension shear stresses will be small.

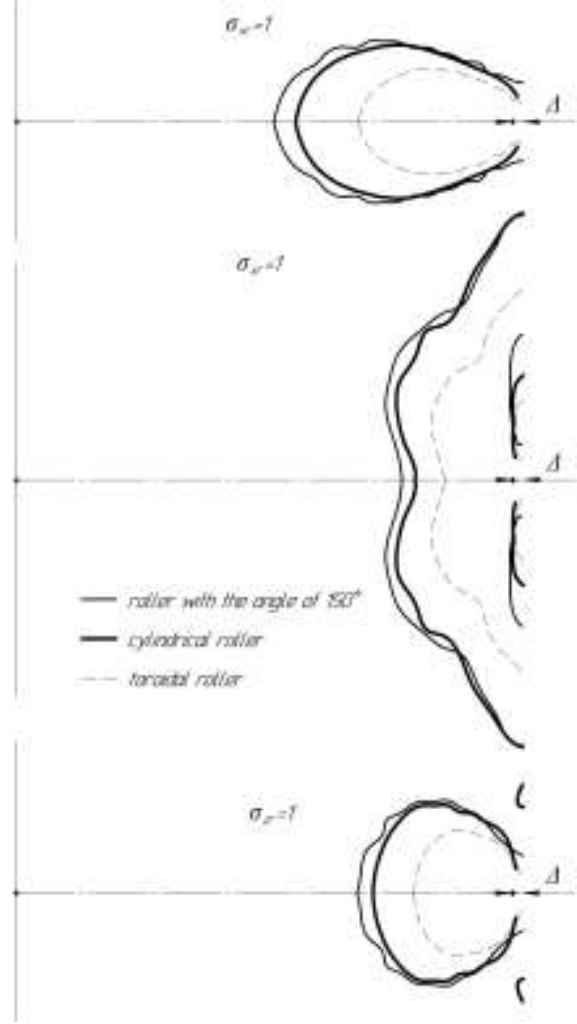

Fig. 10. Isolines of the compression stresses, illustrating the boundary between the zones of plastic and elastic strains $\Delta r=0.020$.

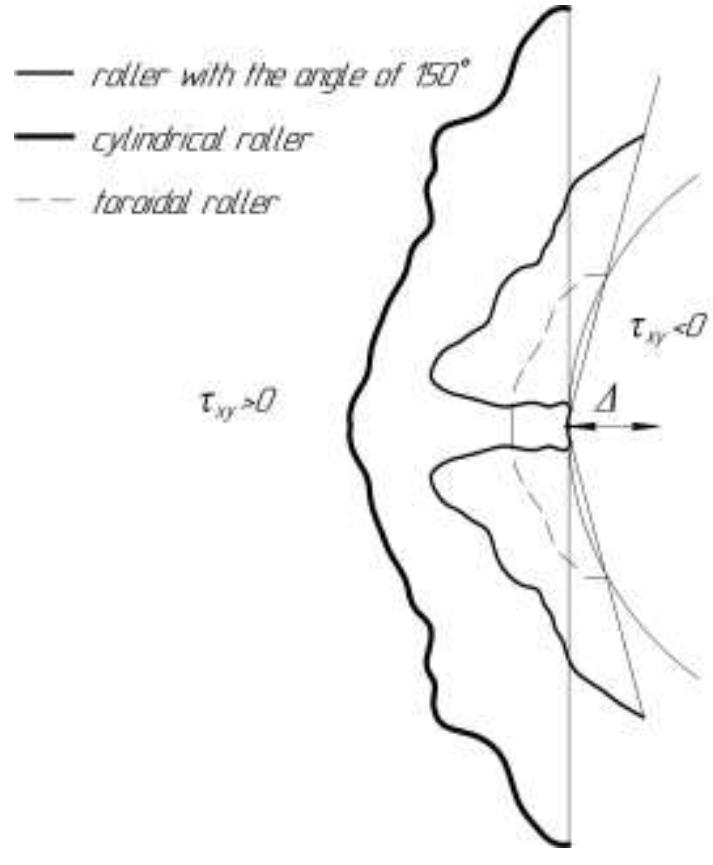

Fig. 11. Isolines $\tau_{\mathrm{xy}}=0$ with $\Delta \mathrm{r}=0.020$.

\section{CONCLUSION}

In this paper, numerical mathematical simulation of the strengthening combined local loading of the deformation zone in the process of penetration of indenters of different shapes into the piece body was considered. The simulation results were presented in the form of a pattern corresponding to Odkvist parameter change depending on the type of the tool and the depth (force) of its penetration into the piece body. Based on the analysis of numerical mathematical simulation data, practical recommendations were formulated pertinent to the selection of the indenter shape for the processes of gradient strengthening of machine parts in the conditions of the combined local loading of the deformation zone. These recommendations may be completely used for the processes of the roller burnishing and will be useful in searching for the optimal relations between the required depth of the strengthened layer and the value of surface hardness [20].

This paper was prepared under the project of "Engineering center of digital medium processes providing integrated safety and security: telecommunications, communication facilities and energy efficiency" within the tender on granting of the public support for the projects pertinent to the foundation and development of engineering centers based on higher education institutions, subject to the general jurisdiction of the Ministry of Education and Science of the Russian Federation.

\section{References}

[1] V.A. Golenkov, S.Yu. Radchenko, D.O. Dorokhov, and G.P. Korotkii, "Scientific Foundations of Strengthening via the Combined Local Deformation", Moscow: Mashinostroenie; Oryol: State University, UNPK, 2013

[2] V.A. Golenkov, S.Yu. Radchenko, D.O. Dorokhov, and I.M Gryadunov, "Classification of the combined local deformation 
processes", Fundamental and Applied Problems of Engineering and Technology, no. 6, pp. 85-89, 2010.

[3] G.D. Del, "Determination of Tension in Plastic Area on Distribution of Hardness", Moscow: Mashinostroenie, 1971.

[4] A.V. Tretyakov and V.I. Zyuzin, "Mechanical Properties of Metals and Alloys When Forming”, Moscow: Metallurgiya, 1973.

[5] G.E. Arkulis, "Theory of Plasticity: Manual for Higher Education Institutions", Moscow: Metallurgiya, 1987.

[6] O.L. Tolokonnikov, A.A. Markin, and V.F. Astapov, "Investigation of the Forming Process with the Finiteness of Deformation Taken into Account", Applied Mechanics, vol. 19, no. 10, pp. 122-125, 1983.

[7] A.M. Abrão, B. Denkena, B. Breidenstein, and T. Mörke, "Surface and subsurface alterations induced by deep rolling of hardened AISI 1060 steel", Production Engineering Research and Development, vol. 8, no. 5, pp. 551-558, 2014. http://dx.doi.org/10.1007/s11740-014-0539-x

[8] A. Akkurt, "Comparison of roller burnishing and other methods of finishing treatment of the surface of openings in parts from tool steel $\mathrm{d} 3$ for cold forming", Metal Science and Heat Treatment, no. 53, pp. 145 150, 2011. http://dx.doi.org/10.1007/s11041-011-9358-2

[9] S. Bagheri and M. Guagliano, "Review of shot peening processes to obtain nanocrystalline surfaces in metal alloys", Surface Engineering, vol. 25, no. $1, \quad$ pp. $3-14, \quad 2009$. http://dx.doi.org/10.1179/026708408X334087

[10] H. Hamadache, Z. Zemouri, L. Laouar, and S. Dominiak, "Improvement of surface conditions of $36 \mathrm{Cr}$ Ni Mo 6 steel by ball burnishing process", Journal of Mechanical Science and Technology, vol. 28, no. 4, pp. 14911498, 2014. http://dx.doi.org/10.1007/s12206-014-0135-1

[11] V.A. Golenkov, S.Y. Radchenko, D.O. Dorohov, and I.M. Gryadunov, "Microhardness distribution in the cross-section in case of strain hardening under combined local load", International Journal of Applied Engineering Research, vol. 11, no. 20, pp. 10315-10320, 2016.

[12] I.M. Gryadunov, V.A. Golenkov, O.V. Pilipenko, and S.J. Radchenko, "Hardening treatment by plastic deformation under conditions of the integrated local loading of a deformation zone", International Journal of Applied Engineering Research, vol. 12, no. 21, pp. 11094-11100, 2017.

[13] S.Yu. Radchenko, D.O. Dorokhov, and I.M. Gryadunov, "Evolution of BrOCS 5-5-5 alloy microstructure and mechanical parameters under intensive plastic deformation conditions", Solid State Phenomena, vol. 265 SSP, pp. 157-165, 2017.

[14] O.V. Pilipenko, S.Yu. Radchenko, D.O. Dorokhov, and I.M. Gryadunov, "Connection of Odkvist parameter and values of microhardness when hardening by plastic deformation", International Journal of Applied Engineering Research, vol. 12, no. 13, pp. 3639-3644, 2017.

[15] P.G. Morrev, "A variational statement of quasistatic "rigid-deformable" contact problems at large strain involving generalized forces and friction", Acta Mechanica, no. 222, pp. 115-130, 2011. http://dx.doi.org/10.1007/s00707-011-0516-9

[16] P.G. Morrev and T.V. Fedorov, "A nurbs approximation of experimental stress-strain curves", Journal of Chemical Technology and Metallurgy, vol. 51, no. 3, pp. 341-349, 2016.

[17] P.G. Morrev and V.A. Gordon, "Simulation of surface hardening in the deep rolling process by means of an axial symmetric nodal averaged finite element", Journal of Physics: Conference Series, vol. 973, no. 1, $012013,2018$.

[18] P.G. Morrev and V.A. Gordon, “An axisymmetric nodal averaged finite element", Latin American Journal of Solids and Structures, vol. 15, no. $2, \mathrm{e} 14$.

[19] K. Johnson, Contact Interaction Mechanics, Moscow: Mir, 1989.

[20] S. Radchenko, D. Dorohov, and I. Gryadunov, "The volumetric surface hardening of hollow axisymmetric parts by roll stamping method", Journal of Chemical Technology and Metallurgy, vol. 50, no. 1, pp. 104112,2015 . 